\title{
QFD methodology development
}

\author{
Elena Loginova* and Maria Ostapenko \\ Industrial University of Tyumen, Tyumen, Russia
}

\begin{abstract}
The QFD methodology is a quality tool that helps businesses transform consumer requirements into product specifications. It is necessary to understand the method applicability when working with this methodology, as well as the economic activity areas which the methodology is already using. It is necessary in order to make it easier to adapt the methodology to product/service.
\end{abstract}

Quality is a concept that characterizes all aspects of people's activities. New research related to the quality problem highlights various parts of the product quality management process.

Since 1972, the Quality Function Deployment (QFD) method has been used in Japan's mechanical engineering. By 1987, this method had been widely used all over the world. The methodology has been used in mechanical engineering and other production and service sectors from its initial implementation to the present time [2,13]. Figure 1 shows the classification of the applicability of the method.

\begin{tabular}{|c|c|}
\hline \multicolumn{1}{|c|}{} & $\begin{array}{c}\text { Applicability of the QFD } \\
\text { method }\end{array}$ \\
\hline $\begin{array}{c}\text { Determination of the most } \\
\text { priority characteristics of } \\
\text { existing products for the } \\
\text { consumer (development } \\
\text { strategy) }\end{array}$ & $\begin{array}{c}\text { Determining the most } \\
\text { priority characteristics of } \\
\text { the existing service for the } \\
\text { consumer (development } \\
\text { strategy) }\end{array}$
\end{tabular}

Fig. 1. Classification of the applicability of the QFD method.

This methodology is not standardized in the Russian Federation. However, there is an international (foreign standard) ISO 16355-1:2015 "Application of statistical and related methods to new technology and product development process - Part 1: General principles and perspectives of QFD", which regulates the application of statistical and related methods to new technology and the process of developing a new product. The search for possible examples of using the methodology was carried out in bibliographic and abstract databases and tools for tracking the citation of the paper published in scientific journals and collections.

\footnotetext{
*Corresponding author: ms_ostapenko@mail.ru
} 
Table 1 shows the development of QFD according to business areas.

Table 1. Areas of human economic activities.

\begin{tabular}{|c|c|c|}
\hline \multirow{2}{*}{$\begin{array}{c}\text { Areas of economic } \\
\text { activity }\end{array}$} & \multicolumn{2}{|c|}{ Types of economic activity } \\
\cline { 2 - 3 } Material sphere & Name & Components \\
\hline & $\begin{array}{c}\text { Primary economic } \\
\text { activities }\end{array}$ & $\begin{array}{c}\text { Agriculture, mining, fishing } \\
\text { industry, forestry. }\end{array}$ \\
\cline { 2 - 3 } & $\begin{array}{c}\text { Secondary } \\
\text { economic } \\
\text { activities }\end{array}$ & $\begin{array}{c}\text { Process industry, building industry, } \\
\text { light and foodservice industries. }\end{array}$ \\
\hline Non-profit sphere & & Services and trade \\
\hline
\end{tabular}

In the beginning, we will consider the material sphere of primary economic activities such as agriculture, mining, and forestry.

The paper by Carlos Parra-López, "Integrating public demands into the model-based design for multifunctional agriculture: An application to intensive Dutch dairy landscapes," examines the application of the methodology for studying the agricultural landscape based on animal husbandry in the North Frisian forests, the Netherlands.

QFD was used in conjunction with the analytical network process (QFD/ANP) to estimate non-market net profit. Social net benefits depended on land use, i.e., the management regimes of pasture in each agricultural field and the presence or absence of hedges around the fields. Changes in market net benefits were expressed in terms of changes for farmers, consumers, and the government. Changes in non-market net profit were expressed in terms of changes in the landscape's quality, the importance of nature, and environmental health - the data based on Dutch public opinion polls.

According to the paper "Integrating public demands into the model-based design for multifunctional agriculture: An application to intensive Dutch dairy landscapes," the use of the QFD methodology in the agricultural sector is more widespread abroad, and there is little information on this topic in Russia. It means that this method is still not widely used in this area on Russian territory.[1]

In the paper "Development of modern approaches to quality management of extracted minerals" by E. V. Freidina, the QFD methodology reduces the risk level in determining a field's investment potential. As a result, applying the QFD methodology for product quality planning contributes to the sustainable investment potential implementation. It aimed at systematizing the transformation of consumer requirements into the quality characteristics of the expected products. This method allows for increasing the usefulness of activities for the development of potential investment resources. Adherence to the QFD methodology will allow the management of mining enterprises and consumers of coal products to be confident that the planned quality will be achieved, and the manufacturer will ensure longterm success in the fuel market. [2]

Secondary economic activities introduction will be considered further in the text.

The QFD methodology is often used in the initial stages of product production, i.e., at the development stage. The methodology helps to correctly identify the characteristics that affect the consumer's demand for these products in the future and eliminating costs.

The most popular areas of use for QFD are various branches of mechanical engineering. In the beginning, we considered the aircraft industry, using the example of the paper "Deploying the quality function for a new concept of a standing cabin of a commercial transport aircraft" by Norhafizah M. Dasuki. It explores the process of designing and developing a suitable seat by setting design and parameter requirements using QFD. Since some airlines connect with the approval of passengers, let on short flight cabins with standing seats. As a result, a seat's approved vertical design for a standing cabin was lacking.[3] 
In the paper "Using quality function deployment in manufacturing strategic planning" by Thomas J. Crowe, Chao-Chun Cheng describes efforts to expand the use of QFD to develop a production strategy. QFD was initially developed and applied as a powerful tool for a similar product, and process design is widely using in the industry as a method within Total Quality Management (TQM). This approach has recently been applied to strategic planning. The authors describe how traditional QFD concepts and methods can be used in production strategy formation to ensure compliance with the business strategy. A case study at a powder metal manufacturing plant is presented, showing how the QFD methodology can be adapted to develop a production strategy [4].

Next, we will consider the instrument-making. In the paper "Development of the QFD methodology on the example of the production of elongated shaped charges," by Laptev $\mathrm{N}$. I. demonstrates how the methodology solves the problems of constant monitoring of the level of demand, determining the relationship between consumer requirements and the characteristics of elongated shaped charges, analyzing the quality level of competitors' products, determining the direction of elongated shaped charges development. It is based on an analysis of customer requirements or the organization's position in the market. Identification of "bottlenecks" in the production of elongated shaped charges is an auxiliary method. This method is related to the current level of the enterprise's resources quality and the requirements for the products of the outsourcer and/or supplier. We can conclude that the QFD methodology solves several problems necessary for production [5].

The paper Savchenko N. O., Kleymenova N. L., Igumenova T. I., Zhashkov A. A., 2016 "Analysis of the quality of the manufacture of cuffs rubber reinforced with the use of the QFD method" considers the relevance of developing high-quality rubber reinforced cuffs. Based on various fillers, to prevent leakage of the working liquid and increase the cuffs reliability under a wide range of loads. Customer satisfaction is considered for improving the quality of cuffs, and a fundamentally new method of strengthening the rubber compound is proposed, which will improve the quality characteristics.

As a result of using the QFD methodology, the following technical characteristics were selected for improvement:

- conditional strength;

- cross-link density;

- mass change after exposure to the standard liquid.

The analysis decided to improve the technical characteristics by making changes to the rubber compound's formulation and optimizing the physical and mechanical parameters. The use of the QFD method helped to analyze the quality of rubber cuffs reinforced with a fullerene-containing filler. Based on the results, we identified the most priority technical characteristics for further research and quality improvement recommendations [6].

We considered using QFD at an early stage, such as in facility design. It is demonstrated in the piece "QFD - method of macro-design of metal-cutting machines." Because of the modern metal-cutting machines, facility design is quite complicated and painstaking work. Therefore, newly established machine tools must be technically and aesthetically perfect and capital saving. The main goal and designing facilities task are to create machines that, at the time of their delivery to the consumer, would be of the same quality as the best samples and higher. Particular attention should be paid to the macro-designing step, which specifies the values of engineering characteristics that specifies the technical level of future products. In turn, the schemes of the macro-design step are difficult to automatic performance because of their dwarflike formalization. The level of formalization was improved by using the QFD method. The QFD theory allows formalizing schemes for finding the optimal values of engineering curves. The values set for the automatically controlled drawing up of the technical specification of the metal-cutting machine allowed us to develop effective procedures [7]. 
The most extensive application of this technique is in the foodservice industry.

In the paper by Priymak E. V. "Application of the QFD method for improving the quality of bakery products", the QFD methodology is used to maximize the satisfaction of the population's food needs. Nowadays, when the demander has the opportunity to choose the desired product from a variety of products in the marketplace, the most critical factor in the manufacturer's success is the quality of its products. When considering different variations in the labels of bakery products, one of the most popular options with the addition of iodine was chosen. [8] The QFD methodology is used in the sphere of food production and the sphere of organization and service of mass catering. The article "Quality function deployment modified for the foodservice industry: An example of a granola bar" observes the quality house construction based on the example of granola bars. Since the percentage of unsuccessful launches of new food products is high, almost $50 \%$ of new products are removed from the marketplace within a year after their launch. It is necessary to maintain the competitiveness of food products and ensure their longevity in the marketplace. Time to market, customer-needs based development, domestic business communications, and product quality are critical factors in this regard. Implementation methodology (QFD) - is a tool for product design based on customer needs, which has the advantage of reaching a compromise between customer needs and production process. It also reduces production costs and reduces production periods. Accordingly, this tool is well suited to all the needs in the development of new products in the foodservice industry. This study used a granola bar as an example to demonstrate a 7-step QFD model. The main ingredients of the bar were oats, nuts, grains (sesame and pumpkin) and dry fruits. They considered a bar produced by a Taiwanese manufacturer and three different brands of manufacturers from foreign countries, selected as competitors based on the sales rating. The focus group consisted only of women because, in Taiwan, muesli bars are mostly consumed by women. The constructed QFD matrix for granola bars reflected relative technical priorities and essential aspects of customer needs, by including competitive analysis. The paper suggests that this methodology is a practical tool for developing new food products [9].

Next, we will consider the use of the QFD methodology in the non-profit sphere for tertiary business activities such as services and trade.

The QFD methodology is used in the field of education, for example, as in the article "BUILDING QFD MODEL FOR TECHNICAL EDUCATION", authors Somadatta Karanjekar, Ramesh R. Lakhe and Vishwas S. Deshpande, the problem of qualified personnel lacking and other resources is considered, which is the main reason for the low quality of student education. The construction of the QFD matrix for this problem allowed to find ways to solve the problem. Namely, the top management should mainly focus on student development activities, and there should be programs and activities for students. More attention should be paid to explaining the basic concept of students. The academic staff should also be very well prepared before going to the lecture. To improve academic standards, academic staff must also develop an interdisciplinary understanding, and they must have excellent communication skills. [10]

In the paper "Deployment of the quality function in higher education" by N. V. Dubrovskaya and E. S. Mishchenko, the problem of high competition in the field of student recruitment by higher education institutions is considered. As students are the primary consumers of learning services, and meeting their learning needs is one of the institution top priorities. After students receive learning services, they will acquire specific knowledge, skills and abilities and become competent specialists in a particular field, so after graduation, students become the "main product" of higher education. [11]

A review of individual papers shows that QFD has not been implemented as a TQM tool for developing and improving the lesson plan on a long-term basis. Rapidly changing 
customer's demands may be considered late and may lead to lower satisfaction levels. It is essential to organize the process of automatically swelling or changing the requirements of the employer and the corresponding competencies of students. Despite numerous studies on the use of QFD, there is no information about the use of QFD to "translate" the employer's requirements into the necessary competencies of students, which should be taken into account in the curriculum. Graduates are expected to achieve a comprehensive set of competencies that reflects their level of professionalism. However, it is not yet clear whether higher educated graduates will have these competencies, in other words, whether the potential quality will coincide with the real one or not. Research in the QFD sphere is not widespread in most areas of education, so QFD is not sufficiently adapted and developed. Further studies should be conducted in order to demonstrate the possibility of using QFD to improve the curriculum in terms of a set of student competencies as one of the primary outcomes of the learning process.

The paper "Application of Quality Function Deployment for the development of an organic product" observes the construction of QFD, as the demand for organic food has increased. People are getting to know more about the health effects of chemical residues in food. Many researchers emphasize that the growing consumer demand for organic food has led to the development of international trade in organic agricultural products.

Organic food products manufacturing has grown both on cultivated land and in the number of manufacturer and consumer marketplaces. In comparison, organic food is a small part of agriculture. The growth of organic agriculture is observed because traditional agriculture is based on the intensive use of chemicals. Consumers view the traditional production system as a possible risk to their health and the environment and are looking for eco-friendly products. Organic farming is a production system that aims to achieve a better quality of life for those who manufacture and consume food. Given the demand and marketplace for this product's type, further growth is projected in this fraction of the marketplace.

This work is aimed at demonstrating the use of QFD in the development of an organic product, i.e. organic fruit jelly. The following sections present the concept of QFD and its use in food development, describing the research methods and procedures used to conduct this work, and provides a proposal for applying QFD to organic product development. Finally, conclusions are drawn from this work.

It can be concluded that the consumption of organic food is increasing worldwide as people become more concerned about the health and the environment. In order for food products to be certified organic, they must meet certain demand criteria, such as specific statutory requirements, including the type of young plants used, manufacturing, transportation, adding ingredients in the production process, and processing the final product. In this sense, QFD can benefit the relationship with the consumer by identifying the necessary qualities of an organic product, linking them to the production chain, extracting quality characteristics, and establishing relationships with the production process and primary produce. [12]

The search for information took place both in foreign and Russian scientific and information resources. It can be summed up that the introduction and dissemination of the QFD methodology have not yet taken place in all types of human economic activity. The results are shown in Table 2. 
Table 2. Analysis of papers using the QFD methodology in foreign and Russian information resources

\begin{tabular}{|c|c|c|c|}
\hline \multicolumn{2}{|c|}{ Types of economic activity } & Foreign information & Russian information \\
\hline \multirow{4}{*}{$\begin{array}{l}\text { Primary } \\
\text { economic } \\
\text { activities }\end{array}$} & The agriculture & More than 10 papers & Less than 5 papers \\
\hline & The mining & Less than 10 papers & Less than 5 papers \\
\hline & The fishing industry & Less than 5 papers & Less than 5 papers \\
\hline & The forestry & Less than 5 papers & Less than 5 papers \\
\hline \multirow{4}{*}{$\begin{array}{l}\text { Secondary } \\
\text { economic } \\
\text { activities }\end{array}$} & The process industry & More than 10 papers & Less than 10 papers \\
\hline & The building industry & More than 10 papers & More than 10 papers \\
\hline & The light industry & More than 10 papers & More than 10 papers \\
\hline & The foodservice industry & More than 10 papers & More than 10 papers \\
\hline \multirow{2}{*}{$\begin{array}{c}\text { Tertiary } \\
\text { economic } \\
\text { activities }\end{array}$} & The services & More than 10 papers & More than 10 papers \\
\hline & The trade & More than 10 papers & More than 10 papers \\
\hline
\end{tabular}

Based on Table 2, it can be concluded that in foreign countries, the QFD methodology is extensively studied and implemented in agriculture, light and foodservice industries, process industry, building industry, as well as in services and trade. According to Russian scientific and information resources, the methodology is extensively studied and implemented in construction, light and foodservice industries, services, and trade. As a result, out of the ten considered components of economic activities, the methodology is well implemented in foreign countries in the seven components, and in Russia in the five components. It shows that the improvement and analysis of consumer characteristics, work on product quality in Russia is not sufficiently developed.

Using the QFD methodology in the development or design of products, organization of any services, or search for shortcomings of existing ones, helps the manufacturer to erase the boundaries between the consumer and the manufacturer. They are allowing the former to hear the requirements of the latter and implement them in their business or product. Nowadays, this is necessary in order to create a process or service that is in high demand in the marketplace. This methodology is not standardized in the Russian Federation. It is used only by the scientific research of foreign, and as a result of domestic authors. Since quality is currently an essential criterion in the manufacturing or services, and foreign countries actively use various tools to improve quality in their activities, we believe that Russia should also actively focus on the quality of products and services and standardize activities to improve the characteristics of quality tools, including standardizing the QFD methodology using (deployment of quality functions) in Russian-made industries.

\section{References}

1. C. Parra-López, C.J. Groot J, C. Carmona-Torres, A.H. Rossing W, Integrating public demands into model-based design for multifunctional agriculture: An application to intensive Dutch dairy landscapes. Ecological Economics (2008)

2. E. V. Freidina, Development of modern approaches to quality management of extracted minerals, Vol 3, No.1 225-231

3. M. D. Norhafizah, Journal of Me-chanical Engineering: Vol SI 5, No.2, 247-257 (2018)

4. J. Crowe, Thomas and C. Cheng. "Using quality function deployment in manufacturing strategic planning." (1996) 
5. N. I. Laptev, «Development of the QFD methodology on the example of the production of elongated shaped charges», Tidings of the Samara scientific center of the Sciences Russian Academy

6. N.O. Savchenko, N.L. Kleymenova, T.I. Igumenova, A.A. Zhashkov, Proceedings of the Voronezh State University of Engineering Technologies, No.1 159-163 (2016)

7. A. S. Firsov, Vestnik of Vitebsk State Technological University ", No.5, 72-77 (2003)

8. E. V. Priymark, A.M. Mukhametshina, T. N. Shigabiev, Scientific notes of

9. Kazan State Academy of Veterinary Medicine named after N.E. Bauman, Vol. 208, No.4, 99-104 (2011)

10. T. Wang, , H. Hsiao, W. Sung, , European Journal of Business and Social Sciences, Vol. 3, No.1, 137-145 (2019)

11. S. Karanjekar, Building QFD model for technical education: students as stakeholders, International Journal of Mechanical and Production Engineering Research and Development (IJMPERD).

12. N.V. Dubrovskaya, E.S. Mishchenko, Engineering education, No.23, 197-202

13. J. Cardoso, N. C. Filho, P. Miguel, Application of Quality Function Deployment for the development of an organic product, Food Quality and Preference (2014) 